\title{
AVALIAÇÃO DO TEOR DE CASEÍNA E ALBUMINA NO LEITE DE VACAS DA RAÇA GIROLANDA
}

\section{EVALUATION OF CASEIN AND ALBUMIN LEVELS IN THE MILK OF GIROLANDA COW}

João R de Freitas Filho, Wandemberg Rocha Freitas, Rodrigo da Silva Lima, Mábio Silvan José da Silva, Roberta Timóteo Lima, Higor Borges Souza, Vânia A. Macário Lima.

Universidade Federal Rural de Pernambuco - UFRPE/ Unidade Acadêmica de Garanhuns - UAG Garanhuns-Brasil joaoveronice@yahoocom.br

\begin{abstract}
Resumo
O trabalho foi realizado com o objetivo de avaliar o teor de caseína e albumina no leite de vacas da raça Girolanda em diferentes fases de lactação. O período experimental teve duração de 45 dias (dezembro/2005 a janeiro/2006), dividido em duas fases: I- avaliação o teor de caseína e albumina; II- investigação os efeitos de climatização, número de ordenha, alimentação e manejo. Os resultados indicam redução do teor de proteínas, e consequentemente, redução da quantidade de caseína e aumento proporcional do teor de albumina. Concluiu-se que vacas Girolanda alimentadas a base de capim-elefante, silagem de milho e farelo de algodão elevou o teor de proteínas.
\end{abstract}

Palavras-chave: leite, proteinas, vaca girolanda.

\section{Introdução}

O leite constitui-se em um alimento rico sob o ponto de vista nutritivo para o a homem. É uma mistura complexa, nutritiva e estável em gordura, proteínas e outros elementos sólidos, que se encontram suspensos na água e constituem o parâmetro de composição que define a qualidade do leite [1].

No Brasil, os sistemas de produção do leite baseiam-se, em sua maioria, em animais da raça Holandesa e de seus cruzamentos com outras raças, principalmente as de origem zebuína, como o Gir leiteiro e o Guzerá.

O leite ao ser retirado da vaca, já contém uma certa quantidade de microrganismos que são normalmente encontrados no animal e que saem durante a ordenha. Após a retirada, o leite pode receber, do meio ambiente, vários microrganismos contaminantes. Outro aspecto importante que 
pode influenciar na qualidade desse alimento é a saúde dos animais, já que muitas doenças dos bovinos podem ser transmitidas para o ser humano. A limpeza da sala de ordenha atua de maneira decisiva sobre a qualidade do leite, de modo que, quanto mais limpa e protegida de correntes de ar, melhor será a qualidade do produto.

Segundo VIANA [2], o Brasil possui hoje um dos maiores rebanhos do mundo, porém com média produtiva de $3,8 \mathrm{~kg} / \mathrm{vaca} / \mathrm{dia}$, abaixo da média mundial (7,8kg/vaca/dia) e 3,6 vezes menor que a média dos países desenvolvidos (13,8 kg/vaca/dia). Acredita-se que as razões para este desempenho inferior é devido a vários fatores, entre eles: a utilização de raças não apropriadas e utilização de instalações inadequadas, a alimentação fora dos padrões exigidos. No que se refere aos componentes do leite, as proteínas e a gordura podem sofrer alterações nos seus níveis e componentes. Porém, o teor de proteína do leite pode variar de 0,3 a $0,4 \%$ [3]

Os componentes naturais do leite podem ser classificados como principais e secundários quanto a sua contribuição por unidade de massa. Os proincipais são á água, a gordura, as proteínas e a lactose, enquantos os componentes secundários englobam basicamente os minerais e as vitaminas. Os principais fatores que afetam a composição natural do leite são a dieta, a constituição genética, a estação do ano, o estágio de lactação, o manejo de ordenha e a sanidade [4].

O leite de vacas contém aproximadamente 3,5\% de proteínas, das quais 2,9\% representado pela caseína e $0,6 \%$ pelas proteínas do soro do leite. Assim, as caseínas representam cerca de $80 \%$ do total de proteínas do leite bovino, as proteínas do soro representam de 15 a $20 \%$, enquanto que as proteínas da membrana dos glóbulos de gordura podem chegar próximo de 5\% do total [5].

Segundo WALSTRA \& JENNESS [6], as caseínas são um grupo de fosfoproteínas específicas do leite as quais se precipitam com acidificação a $\mathrm{pH} 4,6$, como a $\alpha_{\mathrm{s} 1}, \alpha_{\mathrm{s} 2}$, $\beta_{\mathrm{s} 1}$ e $\kappa-$ caseínas, junto com alguns derivados formados por proteólise destas. As proteínas do soro consistem em um grupo bastante diversificado de proteínas, as quais se mantém em solução a pH 4,6, como a $\alpha$-lactoalbumina, $\beta$-lactoglobulina, albumina do soro bovino (BSA) imunoglobulinas e péptides de baixo peso molecular provenientes da hidrólise das caseínas.

A membrana do glóbulo de gordura contém cerca de $50 \%$ de proteínas, que corresponde aproximadamente a $1 \%$ das proteínas totais do leite. Alguns destes compostos protéicos são enzimas e outros são componentes não enzimáticos, como a fração 3 da protosepeptona. Tais proteínas são de difícil estudo pois apresentam uma difícil interação entre si e com os lípides, além de muitas serem insolúveis.

Diversos fatores influenciam a composição e distribuição das frações nitrogenadas do leite bovino. Entre os fatores considerados como de ordem natural podem ser citados: temperatura ambiente, doenças do animal, estágio de lactação, número de parições, raça, alimentação e teor 
energético da alimentação [7]. Do ponto de vista tecnológico, as alterações de temperatura devem ser consideradas como o principal fator de estudo.

Dessa forma, o presente trabalho foi conduzido com o objetivo de avaliar o teor de caseína e albumina isolado de leite de vacas da raça Girolanda em diferentes fases de lactações.

\section{Materiais e Métodos}

\subsection{Materiais}

O presente trabalho foi realizado no laboratório de Química Orgânica, da Unidade Acadêmica de Garanhuns/UAG, da Universidade Federal Rural de Pernambuco, Campus de Garanhuns/PE, no período de dezembro de 2005 a janeiro de 2006, e foi dividido em duas fases.

$\mathrm{Na}$ primeira fase, foram utilizados leites de 16 vacas em lactação da raça Girolanda com grau de sangue $3 / 4$, das Fazendas designadas de $\mathrm{A}, \mathrm{B}$ e C. A coleta do leite a ser analisado foi feita às 4:30h e 17:00h em dias alternados.

A segunda fase consistiu na avaliação climática no curral, número de ordenha, período de lactação e alimentação que o animal era submetido. Essa fase foi realizada com as mesmas vacas para justificar a redução do teor de proteínas nos leites analisados em diferentes fases de lactação.

\subsection{Métodos}

O método utilizado para análise de caseína e albumina nas amostras de leite foi o método do Kjeldahl, modificado. Este método consiste na precipitação da caseína em pH 4,6 com solução de ácido acético.

Nos primeiros quinze dias do mês de dezembro os animais foram alimentados, no intervalo da ordenha, com capim elefante (Pennisetum purpureum, Schumack), farelo de algodão, farelo de milho e casca de mandioca.

A partir do décimo quinto dia as vacas foram alimentadas a pasto com volumoso de capim elefante, no intervalo entre ordenha.

As amostras do leite da $1^{\mathrm{a}}$ e $2^{\mathrm{a}}$ ordenha foram coletadas por animais (em fases de lactação diferentes), para determinação do teor de albumina e caseína.

\subsection{Delineamento Experimental}

As amostras de leite cru foram submetidas ao aquecimento a partir da temperatura ambiente até que atingissem temperatura próxima ao seu ponto de ebulição. As duas (2) temperaturas definidas para análise foram: $40{ }^{\circ} \mathrm{C}, 100{ }^{\circ} \mathrm{C}$. 
Em duas amostras distintas de um mesmo leite foram realizados dois tratamentos, consistindo de aquecimento a partir da temperatura ambiente $\left(25{ }^{0} \mathrm{C}\right)$ até $100{ }^{0} \mathrm{C} .$. Os referidos tratamentos diferiram com relação aos intervalos de tempo: o primeiro de 5 minutos e o segundo de 15 minutos entre a primeira temperatura $\left(25{ }^{\circ} \mathrm{C}\right.$, ambiente $)$ e a ótima $100{ }^{\circ} \mathrm{C}$

As amostras que sofreram aquecimento nos diversos tratamentos foram previamente resfriadas à temperatura ambiente, para então serem realizadas as análises. Foram executadas duas repetições para cada tratamento com as análises individuais de caseína e albumina.

O primeiro passo consistiu na determinação do soro do leite da caseína, para isso, coloca-se $200 \mathrm{ml}$ de leite em um béquer aquecendo-o até ficar morno $\left(40{ }^{0} \mathrm{C}\right)$, mas sem ferver. Em seguida, retira-se do fogo acrescentou-se aos poucos $10 \mathrm{~mL}$ de vinagre, até que se formem grumos de um material branco. Logo após, filtra-se o precipitado de caseína e transfere para um balão de Kjeldahl e determinada a quantidade de caseína neste resíduo, conforme técnica de determinação de nitrogênio total. O resultado é expresso em \% de caseína massa/volume.

O segundo passo consistiu no isolamento da albumina, a qual foi isolada da seguinte maneira, pegou-se o soro do primeiro passo aquecendo-o até ferver $\left(100{ }^{0} \mathrm{C}\right.$ ). Após 15 (quinze) minutos de fervura verificou-se a formação de grumos que foi identificada como outra proteína do leite: a albumina. Filtra-se o soro ficando a albumina retida no papel filtro.

O experimento de campo e em laboratório teve duração de 45 dias e foi realizado segundo procedimentos descrito na literatura $[8,9]$.

\section{Resultados e Discussão}

Uma série de fenômenos ocorre quando o leite é submetido a aquecimento, em razão de seus constituintes se apresentarem em solução (sais minerais e lactose); em emulsão (lipídeos) e em estado coloidal (proteínas) e das possíveis interações químicas entre estes. Alterações no equilíbrio salino, na solubilidade de proteínas, na acidez, no $\mathrm{pH}$, nas reações de escurecimento e várias outras são bastante conhecidas. Do ponto de vista das proteínas, a principal alteração consiste na desnaturação protéica, fenômeno este dependente tanto da intensidade do aquecimento quanto do tempo de aplicação do calor.

Segundo dados da literatura o leite de vacas contém aproximadamente 3,5\% de proteínas. Ao realizar os experimentos utilizando $100 \mathrm{~mL}$ de leite, de diferentes vacas, diferentes fases de lactação e diferentes fazendas (A,B,C), observou-se redução nos teores de proteínas. Na tabela 1, são apresentados os resultados obtidos. Vale destacar que os resultados expressos na tabela 1 foram obtidos após as vacas ser sumetidas a uma dieta contendo farelo de milho, farelo de algodão e 
casca de mandioca e após um período de 45 dias. Antes de submetermos as vacas a dieta acima citada, foi realizado um expeirmento para determinação do teor de proteínas e obttivemos resulatdos muito abaixo dos expressos na tabela, ou seja em torno de $2,35 \%$.

Tabela 1: Composição percentual de proteína total (PT), caseína (Cas) e albumina (Alb) em diferentes fases de lactação de leite de vacas

\begin{tabular}{|c|c|c|c|c|c|c|c|c|c|}
\hline \multirow[t]{2}{*}{ Fazenda } & \multicolumn{3}{|c|}{ Primeira Lactação } & \multicolumn{3}{|c|}{ Segunda Lactação } & \multicolumn{3}{|c|}{ Terceira Lactação } \\
\hline & PT & Cas & Alb & PT & Cas & Alb & PT & Cas & Alb \\
\hline A & 3,05 & 56,42 & 43,58 & 3,10 & 58,56 & 41,44 & 3,08 & 51,93 & 48,07 \\
\hline B & 2,89 & 57,01 & 42,99 & 2,95 & 58,72 & 41,28 & 2,90 & 58,37 & 41,63 \\
\hline $\mathrm{C}$ & 3,15 & 68,05 & 31,95 & 3,20 & 70,90 & 29,10 & 3,15 & 69,05 & 30,95 \\
\hline
\end{tabular}

Analisando os dados da tabela 1 acima, verificou-se que a resposta quando aos teores de proteínas variou com o estágio de lactação. Houve uma depressão na síntese de caseína, ou seja, todos os resultados foram abaixo do descrito na literatura ( $80 \%$ de caseína) e, consequentemente houve um aumento proporcional de soroproteínas, representadas pelas imunoglobulinas e soroalbumina, que compensaram as perdas quantitativas de caseínas.

Acredita-se que esta redução deve-se a vários fatores. $\mathrm{O}$ primeiro fator analisado foi à alimentação, pois quando os animais, em diferentes fases de lactação, foram alimentados com apenas capim a pasto observou-se que a produção de leite caiu e consequentemente o teores de proteínas também. Alimentados os animais com farelo de milho, farelo de algodão e casca de mandioca houve um aumento, em torno de $10 \%$, nos teores de proteínas.

A ingestão de energia é o principal fator nutricional relacionado ao teor e produção de proteína do leite. $\mathrm{O}$ aumento da ingestão de energia atrvavés de fontes de carboidratos ( não através de gordura) aumenta a produção e a porcentagem de proteína no leite. Sabe-se que a ingestão de energia está relacionada à ingestão de matéria seca e à densidade energética da dieta. $\mathrm{O}$ aumento da densidade energética da dieta normalmente é dependente do fornecimento de maior proporção de concentrados na dieta, o que aumenta a produção de ácido propiônico no rúmen do animal. Parece haver uma realção positiva entre a produção de ácido propiônico no rúmen e o teor de proteína no leite. Alguns pesquisadores acreditam na tese de que a população de micrioorganismos que têm o ácido propiônico como principal produto final da fermentação ( principalmente aqueles que digerem amido) devem possuir perfil de aminoácidos mais adequado à sintese de proteína do leite.

Vacas alimentadas com ração de melhor qualidade dão leite com $0,28 \%$ de gordura e $0,11 \%$ a mais de sólidos desengordurados logo após o parto, durante os três primeiros meses, quando 
comparado com vacas alimentadas só a pasto. Por outro lado, sabe-se que a subalimentação das vacas pode ser o responsável pela redução na porcentagem de proteínas do leite, assim como uma redução no seu rendimento. Assim, dieta pobre em fósforo $(\mathrm{P})$ e a suplementação da dieta com gordura levará a uma redução na porcentagem de proteínas.

Um outro fator que levou em consideração foi às condições de instalações dos animais. $\mathrm{O}$ curral onde as vacas foram confinadas contribuiu para a redução dos teores de proteínas. Pois, sabese que a falta de climatização nas instalações onde os animais são confinados leva a uma perda na produção de leite na ordem de $10 \%$ quando comparados com animais submetidos a ambientes climatizados [10] (Head, 1995).

Vários trabalhos confirmam as mudanças físico-químicas nas diferentes frações protéicas e, consequentemente, na distribuição do nitrogênio das mesmas. As proteínas do soro são as mais termolábeis, pois, ao contrário das caseínas, não foram micelas, encontrando-se molecularmente dissolvidas e suscetíveis à desnaturação térmica. Entre estas, a $\alpha$-lactoalbumina é a mais resistente, seguida por $\beta$-lactoglobulina, albumina do soro e imunoglobulinas. A resistência intrínseca das caseínas ao calor é devido ao fato de apresentarem muitos resíduos de prolina em sua estrutura primária, o que dificulta a formação de pontes de hidrogênio. Isto confere uma estrutura espacial parcialmente “desnaturada” às caseínas.

\title{
4. Conclusões
}

A análise do leite das diferentes vacas da raça Girolanda, em diferentes fases de lactação, mostrou uma redução no teor de proteína total, redução da quantidade de caseína e aumento do teor de albumina.

O curral onde as vacas foram confinadas, não climatizado, contribuiu para a redução dos teor de proteínas.

Quando os animais foram alimentados com farelo de milho, farelo de algodão e casca de mandioca houve um aumento de aproximadamente 10\% nos teores das referidas proteínas.

A inclusão de gordura na dieta das vacas contribuiu para redução do teor de proteínas.

\begin{abstract}
The work was carried out with the objective to evaluate the casein and albumin levels in the milk of Girolanda cow after several lactation periods. The experimental period lasted 45 days (december/2005 and january/2006) and was divided in two phases as follows: I- to evaluate the casein and albumin levels; II- to investigate the climatization effects, feeding, handling. The results indicate the reduction in the proteins levels consequently reduction casein level and proportional increase of albumin level. It was concluded that Girolando cows fed diets with elephant grass, corn silage and cotton bran were increased proteins levels.
\end{abstract}

Key-words: milk, protein, girolanda cow. 


\section{Referências}

[1] BRITO, J. R. F.; CALDEIRA, G. A. V.; VERNEQUE, R. S.; BRITO, M. A. V. P. Sensibilidade e especificidade do "Califórnia Mastitis Test" como recurso diagnóstico da mastite em relação à contagem de células somáticas. Pesquisa Veterinária Brasileira, v. 17, n.2, p. 49-53, 1997.

[2] VIANA, J. A.C. O terceiro mundo não é assim: está assim. Belo Horizonte: FEP/MVZ, 1999, 689p.

[3] WITTWER, F. Diagnósticos dos desequilíbrios metabólicos de energia. In: GONSALEZ, F. H. D.; BARCELLOS, [4] DÜRR, J.W., FONTANELI, R.S., BURCHARD, J.F. Fatores que afetam a composição do leite. In: Curso de sistema de produção para gado de leite baseado em pastagens sob plantio direto. Pasa]so Fundo. Anais. Embrapa-Trigo, 2000 .

[5] PRATA, L.F. Fundamentos de Ciência do Leite. UNESP, 2001, p.62.

[6] WALSTRA, P.; JENNESS, R. Dairy chemistry and phisics. New York, John Wiley \& Sons, 1984. 423p.

[7] DE PETERS, E.J.; CANT,J.P. Nutritional factors influencing the nitrogen composition of bovine milk: a review. Journal of Dairy Science, 75:2043-70,1992.

[8] LISBOA, J. C. F.; BOSSOIANI, M. Experiências Lácteas. Química Nova Escola, 1997.

[9] SILVA, P.H. F. Desenvolvimento de metodologia analítiica para determinação do teor de caseína em leite e para avaliação da proteólise em queijos. Viçosa, UFV, 1995. 64p. (Tese M.S.).

\section{Dados do primeiro autor:}

Nome completo: João Rufino de Freitas Filho

Filiação institucional: Universidade Federal Rural de Pernambuco

Departamento: Unidade Acadêmica de Garanhuns

Função ou cargo ocupado: Professor Adjunto I

Endereço completo para correspondência (bairro, cidade, estado, país e CEP): Av. Lions Club, Aluísio Pinto, Garanhuns, Pernambuco, Brasil, CEP: 55292-060

Telefones para contato: (87)3762-0438 Celular (87)99995855

e-mail: joaoveronice@yahoo.com.br 